\title{
Women Mental Health and Well-being: A New Paradigm
}

\author{
Mrs. Ashwini. $\mathrm{R}^{1 *}$, Dr. Vijay Prasad. B ${ }^{2}$
}

\section{ABSTRACT}

This paper reviews literature on the determinants of women's mental health through a stigma of mental illness and gender perspectives. This approach stresses that women's particular health needs have been neglected in a male-centred models of health, and argues for the importance of addressing these needs in a way that views women and their lives holistically. A woman in social context is seen as parents and their roles have been demonstrated from their life within the family and society as well. This article draws attention to the women and physical health instead of looking at mental illness alone. The impact of violence against women, in particular, the effects of childhood sexual abuse, domestic violence and rape has been illustrated in western and Indian perspectives. In recommendations initiatives in mental health services especially, for women mental health has been emphasized broadly.

\section{Keywords: Gender, Stigma, Mental Disorder, Wellbeing}

Health and wellbeing in general is a Nobel concept of human kind to measure their quality of life. The definition of health by The World Health Organization (WHO) defined health in its broader sense in 1946 as "a state of complete physical, mental, and social well-being and not merely the absence of disease or infirmity." Similarly, mental health encompasses components of psychological, physical and social well-being. The public health paradigm has gained increasing viability as an alternative, complimentary approach to the medical model. It re-establishes a balanced view of both illness prevention and health promotion. Mental health promotion is any action taken to maximize mental health and well-being among populations and individuals, whereas mental health prevention is concerned with avoiding illness. In 1986, the World Health Organisation defined health promotion as the process of enabling people to increase control over and to improve their health (WHO, 1986). In order to achieve better mental health outcomes for

\footnotetext{
${ }^{1}$ Clinical Psychologist, Dept of Clinical Psychology, Dharwad Institute of Mental Health and Neurosciences (DIMHANS)-Dharwad-Karnataka, India

${ }^{2}$ Associate Professor, Dept., of Clinical Psychology, Dharwad Institute of Mental Health and Neurosciences (DIMHANS)-Dharwad-Karnataka, India

*Responding Author
}

Received: January 09, 2017; Revision Received: February 16, 2017; Accepted: February 24, 2017

(C) 2017 Ashwini R, Prasad V; licensee IJIP. This is an Open Access Research distributed under the terms of the Creative Commons Attribution License (www.creativecommons.org/licenses/by/2.0), which permits unrestricted use, distribution, and reproduction in any Medium, provided the original work is properly cited. 


\section{Women Mental Health and Well-being: A New Paradigm}

women and men we need to tackle the social context of individual behaviour and empower individuals and communities to make positive change.

\section{Mental disorders}

Prevalence rates of depression and anxiety disorders as well as psychological distress are higher for women than for men. These findings are consistent across a range of studies undertaken in different countries and settings (Desjarlais et al., 1995). In addition to the higher rates of depression and anxiety, women are much more likely to be diagnosis diagnosed for obsessive compulsive disorder, somatisation disorder and panic disorder (Russo, 1990). In contrast men are more likely to be diagnosed for antisocial personality disorder and alcohol abuse/dependency. The gender differences associated with mental disorders are brought out most clearly in case of depression (Russo, 1990). Data from the World Bank study revealed that depressive disorders accounted for close to $30 \%$ of the disability from neuropsychiatric disorders amongst women in developing countries but only $12.6 \%$ of that among men. The disparity in rates between men and women tend to be even more pronounced in underserved populations (World Bank, 1993).

\section{Women's Mental Health}

Women represent a special group for mental health care. The need of women from mental health point is well recognized in all populations. Though the overall prevalence of mental and behavioral disorders is not different between men and women, anxiety and depressive disorders are more common among women. Almost all studies show that depressive disorders are 1.5 to 2 times of that in men, during the adult life. The reasons for these differences are partly biological, partly social and psychological. In addition women are more often the victims of domestic violence. Studies in developed countries have shown that women experiencing domestic violence have higher symptoms of psychological distress and greater frequency of contemplation of suicide (Thara, 2004). From all these perspectives, mental health needs of women are greater, of special nature and need interventions that are sensitive to their needs. Specific measures to care to this group would include the following strategies: greater number of women health personnel; specific training to health personnel on gender issues; mental health education about self-care for mental health; support to women to form self-help groups; emotional support at individual and family levels and income generating activities (Thara, 2004).

\section{Stigma of mental disorders in women}

Stigma of mental illness continues to be a major issue in India. Thara and Srinivasan (1998) reported on the beliefs about mental illness from a rural South-Indian community. Thara and Srinivasan (2000) studied the nature of stigma and its relationship to attribution in primary caregivers of 159 urban patients of Madras. Marriage, fear of rejection by neighbour, and the need to hide the fact from others were some of the more stigmatising aspects. Female sex of the patient and a younger age of both patient and caregiver were associated with higher stigma. Attributions to faulty biological functioning, character of lifestyle, substance abuse and intimate 


\section{Women Mental Health and Well-being: A New Paradigm}

interpersonal relationship discriminated between the groups with experiences of high and low stigma. Beliefs about causation of schizophrenia influence the attitudes of patients' families.

\section{Gender Perspectives}

Bringing up female plays a powerful role in shaping women's vulnerability to mental disorders (Taft, 2003), While women may have freed themselves to some extent from the gendered norms of the domesticity and economic dependence of previous generations, they still bear the greater unpaid burden of domestic chores and have not yet achieved economic independence. Women also continue to shoulder, disproportionately, the care of children and sick or elderly relatives. Studies show that combined risks of anxiety and depression have been found to be twice as high for women as for men (Australian Institute of Health and Welfare, 2008) This can, in part, be attributed to negative attitudes towards women, lack of acknowledgement of the work they do, fewer opportunities in education and employment and greater risk of domestic violence (WHO, 2000) Gender also intersects with a number of social factors to make some groups of women more vulnerable to poor mental health. These groups include women with disabilities, single mothers, culturally and linguistically diverse women, indigenous women and same-sex attracted women.

\section{Gender and the research data}

Few people working in mental health would disagree that 'gender is a critical determinant of mental health and mental illness' (WHO, 2008) yet, how many have a clear understanding of why, when we talk about mental health, we need to talk about women (and men), not just people? If we are going to meet sex-specific needs in mental health (and indeed, in health generally), a collection of raw data is not enough; it must be disaggregated or put more simply, count men and women separately. Gendered data seems so obvious, but if you read most government reports and examine much of the research, you will find that gender is often ignored or overlooked. Yet, without gender specific data, policy and program development can only tell part of the story and address only some of the issues.

How else can we know, other than through gender-based research and the data it produces, that 15 per cent of women (compared to ten per cent of men), report high to very high levels of psychological distress (Australian Bureau of Statistics, 2006), that women, while succeeding less, attempt suicide more than men, and that anxiety and depression in women is frequently accompanied by other mental health problems (Guggisberg, 2006). How can we reach women and deliver mental health services responsive to women most in need and understand what may trigger mental illness in women at particular stages of life? How can we plan, provide, tailor, fund and target policy and programs to women if we do not have gendered data available to us? And, how do we work to prevent women developing mental health problems if we do not have evidence to guide us? If we are to be sensitive to diversity as well as gender further disaggregation of gendered data by income, education, age, ethnicity, language, sexual 


\section{Women Mental Health and Well-being: A New Paradigm}

orientation, disability, Aboriginality and geographic location will alert us to the way gender interacts with other social factors to influence mental health. Of course, collection of this data not only helps to better tailor and target policy and programs to women, it will identify needs in male populations, too.

Health policy-makers and practitioners are beginning to recognize the importance of gender issues to health and health care. Interpretations of gender analysis in health fields have been varied but include two main approaches: a women's health needs approach and a gender-equity approach (Standing, 1997). A women's health needs approach is "concerned with the implications for women of difference in the epidemiological profile between the sexes" (Standing, 1997). This approach stresses that women's particular health needs have been neglected as a result of male-centred models of health, and argues for the importance of addressing these needs in a way which views women and their lives holistically; that is, it addresses the full range of women's health problems, rather than just their reproductive health problems, and that it does this throughout the life cycle.

A gender-equity approach is "concerned with the role of gender relations in the production of vulnerability to ill-health or disadvantage within health care systems" (Standing, 1997). So far, it has focused, in particular, on the influence of this on access to and utilization of formal health services. "Equity" can be distinguished from "equality" in that, while equality carries some notion of "sameness", equity carries a notion of "fairness". While a focus on equality would argue that men and women should be treated exactly the same - i.e. not discriminated against in the provision of health care explicitly on the basis of their sex - a focus on equity argues that men and women may have different needs and face different barriers to meeting those needs or to having them met. Additionally, different needs and barriers may not lead to equal disadvantage for both sexes. An equity approach, therefore, stresses that health policy must consider the different and inequitable needs of men and women in allocating resources for health promotion, prevention, and care (Liverpool School of Tropical Medicine, 1998).

In the past decade the number of women living in poverty has increased disproportionately to the number of men, particularly in developing countries. In addition to economic factors, the rigidity of socially ascribed gender roles and women's limited access to power, education, training and productive resources. While poverty affects households as a whole because of the gender division of labour and responsibilities for household welfare, women bear a disproportionate burden, attempting to manage household consumption and production under conditions of increasing scarcity (Nussbam, 2000).

\section{Women in Social context}

The relationship between poor physical health, impaired psychological functioning and deprived socio-economic background is well documented (Gomm, 1996). Women who display self- 


\section{Women Mental Health and Well-being: A New Paradigm}

neglect and self-harming behaviours are exposed to additional problems when trying to secure accommodation, training and employment. The 1992 Health and Lifestyles Survey found that community involvement and social support vary with socio-economic status. Women's health appeared more strongly associated with the social environment than men's (Cooper, Arber., \& Fee, 1999). The quality and number of roles individuals play are important, with evidence that those with the fewest family, friendship, working and community roles have the poorest psychosocial health. More frequent and higher-quality social relationships in women can combat the effects of stress. However, individuals vary and we should avoid over-simplified factors for good mental health such as marriage and occupation (Pollock \& West, 1987). For women, being part of an emotionally and economically rewarding social network would appear to be helpful in determining mental well-being, unless the demands upon the individual create emotional overload.

\section{Women as parents}

Parenting plays an important role, first, in protecting a child from harm and promoting physical and emotional health; second, in setting and enforcing boundaries to ensure the child's and others' safety; and, third, in optimizing the child's potential. Parenting can act as a buffer against adversity such as poverty or delinquent influences, but may also be a mediator of damage, as in child abuse. A reasonable consensus exists about 'bad parenting', but there is no agreement about its opposite. Although the job is complex and demanding, help is fragmented between different services and reactive in nature, doing little to involve the parent or take preventive action (Hoghughi, 1998). Mothers who themselves have had poor experiences of parenting may be the least likely to receive practical help with child care and social support to help them function in their new role (Pound \& Abel, 1996). Lone teenage mothers are an especially vulnerable group. Women threatened with having their children taken into care may distrust services and feel inhibited from seeking help. A significant proportion of women with a severe mental illness have children, but health professionals tend to ignore these women's role as parents, considering parenting as a problem of social services rather than a health issue (Nicholson et al., 1993).

\section{Women's reproductive health}

Women with a mental illness may have less awareness of contraceptive needs, resulting in an increased risk of unwanted pregnancy. They may also be at increased risk of developing a sexually transmitted disease, more specifically having less knowledge of AIDS (Aruffo, Coverdale., \& Chacko, 1990; Coverdale, Turbott., \& Roberts, 1997).

\section{Women and abuse}

There has been increasing awareness of the impact of violence against women, in particular, the effects of childhood sexual abuse, domestic violence and rape.

These would be summarized in the following order: 
Childhood sexual abuse: Women who have experienced childhood sexual abuse are more likely to suffer social, interpersonal and sexual difficulties in adult life. They seem to have particular problems with intimate relationships, owing to difficulties with trust and a perception of their partners as uncaring and over controlling. Abuse may also correlate with an increased risk for a range of mental health problems (Mullen, Martin., \& Anderson, 1994).

Domestic violence: A high proportion of women attending accident and emergency departments report a history of domestic violence, and in this group there is a high level of mental health problems. A history of childhood abuse increases a woman's risk of subsequent mental health problems if she is also abused as an adult. In this double-abuse group, there may also be an increased risk of substance misuse (Roberts, Williams., \& Lawrence, 1998).

Rape: Victims of completed rape are at increased risk of suicide attempts and of having a depressive illness. In addition, perceptions of life threat and actual injury increase the risk of post-traumatic stress disorder (PTSD) (Mezey \& Stanko, 1996).

\section{Psychological wellbeing}

Ryff (1989) conceptualises psychological well-being as a positive component of mental health which can be viewed as a multi-faceted domain encompassing six distinct components, namely; positive self-regard (self-acceptance), mastery of the surrounding environment (environmental mastery), quality relations with others (positive relations with others), continued growth and development (personal growth), purposeful living (purpose in life), and capacity for selfdetermination (autonomy) (Ryff \& Keyes, 1995). Research with Ryff's (1989) scale has revealed that psychological well-being develops through a combination of emotional regulation, personality characteristics, identity and life experience (Helson \& Srivastava, 2001), increases with age, education, extraversion and conscientiousness and decreases through neuroticism (Keyes, Shmotkin \& Ryff, 2002).

\section{Social wellbeing}

Social well-being may be conceptualised according to individuals' perception of social support. Procidano and Helier (1983) conception of perceived social support is understood as the extent to which the individual perceives that his/her needs for support, information and feedback are fulfilled by friends and family. The perception of social support plays an important role in coping behaviour of individuals.

\section{RECOMMENDATIONS FOR SPECIFIC INITIATIVES IN MENTAL HEALTH SERVICES}

\section{Upgrade the quality of mental health services}

Mental health services have a crucial role to play in alleviating suffering associated with psychiatric illnesses, emotional distress, psychological disorders, and behavioural 


\section{Women Mental Health and Well-being: A New Paradigm}

pathology. Abused women, troubled children, those traumatized by political violence, those who have attempted suicide or are addicted to alcohol or narcotics, and especially those who suffer acute or chronic mental illnesses can be helped substantially by competent mental health care. We have seen how women suffer disproportionately from mental illnesses such as depression and anxiety, and dissociative disorders associated with sexual abuse, and yet these are the illnesses that competent clinicians may best help. With recent advances in psychiatric medications and specialized forms of psychosocial interventions, the potential for benefit is greater than at any time in history.

Yet mental health services in most societies are inadequate. Well-trained practitioners are scarce, drugs and psychosocial interventions are unavailable or of poor quality, and even where expertise and resources exist, they seldom reach into the communities where the needs are greatest. The human rights of the mentally ill are often severely compromised, and mental health care is too often associated with abusive social control. Financial investment is required for sustainable programs, and creativity is needed to build programs that join local resources with professional knowledge.

Mainstreaming a gender perspective in the mental health sector through educating women at all levels of society about the possibilities of mental health interventions and the potential for services and programs is central to the success of mental health program development. The development of community based programs may build upon the engagement of many women to their local communities and their commitment to community and family health. Formal mental health services, including rational drug policies for psychotropic medications and the reliable provision of adequate supplies at reasonable costs (selected generic antidepressants, antipsychotic and anticonvulsant drugs), must be complemented by non-medical support groups, consumer groups and healing institutions that provide crucial care in many communities.

\section{Encourage systematic efforts to upgrade the amount and quality of mental health training for workers at all levels, from medical students to graduate physicians, from nurses to community health workers.}

Essential to mental health programs is a small cadre of well-trained mental health professionals: psychiatrists, psychologists, social workers and psychiatric nurses. They are the ones who must lead efforts to establish priorities of mental health in medical education and health policy. Training primary care physicians, nurses and health workers in the recognition and appropriate referral and/or treatment of mental illness is central to expanding community services to meet needs. Specific training in diagnosis and management of psychiatric conditions is required to improve the quality of mental health services offered in primary care. And since community practitioners often depend almost exclusively on agents of pharmaceutical companies for new information on medications, initiatives in continuing education are needed to provide more basic training in the safe and effective use of psychotropic medications. 


\section{Women Mental Health and Well-being: A New Paradigm}

With appropriate training and supervision, nonphysician primary health workers can learn to diagnose, treat, and organize follow-up programs for a substantial fraction of cases of depression, anxiety and epilepsy, and can, with appropriate supervision, manage patients with chronic schizophrenia in the community if their social welfare is provided. WHO has developed training programs and shown they can be effectively employed in societies as diverse as India, the Philippines, and Tanzania. In societies in which nonphysicians provide a substantial portion of primary care, specialized training activities are a cost-effective means of improving and extending mental health services. Mainstreaming a gender perspective may build on the interests of many women professionals who have entered the field of mental health care as psychiatrists, psychiatric nurses, counsellors and social workers.

3. Promote efforts to improve state gender policies, toward interdicting violence against women, and toward empowering women economically, and to make women central in policy planning and implementation of mental health services. Research should evaluate the mental health consequences of these programs for women, for children, and for men. As we have noted above, investing in the health, education, and well-being of women is of high priority for improving the mental health of populations in low and middle income countries. The World Bank's 1993 World Development Report clearly demonstrates that educating women to primary school level is the single most important determinant of both their own and their children's health. World Mental Health (1995) indicates women's education is an equally valuable investment for the mental health of women, men and children. Such education also renders women less likely to tolerate domestic violence and abuse, or the spending of substantial portions of the family income on drinking or gambling by their spouses. Educated women are also more likely to be receptive to and engaged, as equal partners, in public health programs.

Women throughout the world constitute the vast majority of caretakers of first and last resort for chronically disabled family members, including mentally retarded children, demented elderly, and adults suffering a major mental illness. Minimally, it is in a community's long-term social interest to assist with this burden through formal health services. In addition, because women are critical to the success of health policies, their participation in formulating mental health policies should be encouraged, with governments, international organizations and NGOs defining avenues for women to exercise leadership roles. Policies may be evaluated by women's groups not only in terms of how they support women's mental health but also in terms of the quality of services offered to women, children and men.

4. Encourage initiatives to attend to the causes and consequences of collective and interpersonal violence.

Collective and interpersonal violence is one of the most pressing problems in the world today. Wars, prolonged conflicts, ethnic strife, and political repression lead to deep trauma and psychological problems that persist beyond the period of conflict and violence. While 


\section{Women Mental Health and Well-being: A New Paradigm}

only profound changes in international and national politics will reduce armed conflicts, peace and security initiatives should be strongly encouraged. In addition, mental health concerns should be more widely understood in peace and security programs. For ethnic conflict, for instance, mental health issues from the effect of racism on ethnic identity to the vicious cycles of revenge should become the target of new policies, such as education in schools. Transnational initiatives to treat trauma may assist in modest but effective ways as well to quickly respond to and aid victims of collective violence. Intervention programs of therapy and triage, which have been shown to have beneficial effects, need to be supported internationally as well as locally given costs and limited services in many parts of the world. Women's organizations have taken major roles in leading such efforts in the past and can be models for future efforts as well.

Curtailing and preventing interpersonal and domestic violence (often generated by community violence and breakdown) requires the mainstreaming of a gender perspective to formulate policies both in health care services and in the legal system. Although medical care for physical wounds and mental health care for psychological wounds may mitigate long term suffering, deterrence and ultimately prevention require laws that make domestic violence against women (and children) a crime.

5. Direct efforts specific to primary prevention of mental disorders and behavioral, psychosocial and neurological disorders.

Such efforts would survey the scientific knowledge base, examine primary prevention activities around the world, address the cross-cultural relevance of prevention programs, and define training needs and related activities. Successful prevention programs call for the integration of biological and psychosocial factors, and the active promotion of proven preventive programs. Models taking account of the co-morbidity of many disorders, the clusters of psychiatric disorders and psychosocial distress, must be developed in order to encourage interventions to support individuals who are afflicted with mental illness. In addition, prevention programs require an understanding of indigenous protective factors, such as the activities of caretakers of those who are ill and those local practices that enhance the mental and physical health and well-being of individuals and of communities. Listening to women, professional and lay, should help in identifying these factors.

\section{Acknowledgments}

The author appreciates all those who participated in the study and helped to facilitate the research process.

Conflict of Interests: The author declared no conflict of interests.

\section{REFERENCES}

Aruffo, J. F., Coverdale, J. H., \& Chacko, R. C. (1990). Knowledge about AIDS among women psychiatric outpatients. Hospital and Community Psychiatry, 41, 326-328. 


\section{Women Mental Health and Well-being: A New Paradigm}

Australian Bureau of Statistics. (2006). Mental Health in Australia: A Snapshot, 2004-05, Australian Bureau of Statistics, Canberra.

Australian Institute of Health and Welfare. (2008). Mental Health Services in Australia, 20052006, Annual Report, p.16.

Cooper, H., Arber, S., \& Fee, I., (1999) The Influence of Social Support and Social Capital on Health. London: Health Education Authority.

Coverdale, J. H., Turbott, S. H. \& Roberts, H. (1997) Family planning needs and STD risk behaviours of female psychiatric out-patients. British Journal of Psychiatry, 171, 69-72.

Desjarlais, R., Kleinman, A., Eisenberg, L., \& Good, B. (1995). World Mental Health: Problems, Priorities, and Responses in Low-Income Countries. Oxford University Press.

Gomm, R. (1996). Mental health and inequality. In Mental Health Matters (eds T. Heller, J. Reynolds, R. Gomm), pp. 110-120. Buckingham: Open University Press.

Guggisberg, M. (2006). The interconnectedness and causes of female suicidal ideation with domestic violence, Australian Journal for the Advancement of Mental Health (AeJAMH), 5(1), accessed at http://www.auseinet.com/journal/vol5iss1/index.php on 7th August, 2008.

Helson, R \& Srivastava, S. (2001). Three paths of adult development: conservers seekers and achievers. Journal of Personality and Social Psychology. 80, 995-10 I0

Hoghughi, M. (1998). The importance of parenting in child health. Doctors as well as governments should do more to support parents (editorial). British Medical Journal, 316, 1545.

Keyes,C. L.M., Shmotkin, D. \& Ryff, C. D. (2002). Optimising well-being: The empirical encounter of two traditions. Journal of Personality and Social Psychology, 82, 1007-1022.

Liverpool School of Tropical Medicine. (1998). Guidelines for the analysis of gender and health. http://www.liv.ac.uk/lstm/GG-1.html

Mezey, G. \& Stanko, E. (1996). Women and violence. In Planning Community Mental Health Services for Women. A Multiprofessional Handbook (eds K. Abel, M. Buszewicz, S. Davison, et al), pp. 160-175. London: Routledge.

Mullen, P. E., Martin, J. L., \& Anderson, J. C. (1994). The effect of child sexual abuse on social, interpersonal and sexual function in adult life. British Journal of Psychiatry, 165, 35-47.

Nicholson, J., Geller, J. L., \& Fisher, W. H. (1993). State policies and programs that address the needs of mentally ill mothers in the public sector. Hospital and Community Psychiatry, 44, 484-489.

Nussbam, M. (2000). Women and Human Development. New York: Cambridge University Press.

Pollock, L. \& West, E. (1987). Women and psychiatry today. Senior Nurse, 6, 11-14.

Pound, A. \& Abel, K. (1996). Motherhood and mental illness. In Planning Community Mental Health Services for Women. A Multiprofessional Handbook (eds K. Abel, M. Buszewicz, S. Davison ), pp. 20-35. London: Routledge.

Procidano, M. E. \& Helier, K. (1983). Measures of perceived social support from friends and from family: Three validation studies. American Journal of Community Psychology, II (I). 1 - 22.

Roberts, G. L., Williams, G. M., \& Lawrence, J. M. (1998). Women and Health, 28, 117-129. 
Russo, N.F. (1990). Overview: forging research priorities for women's health. American Psychologist. 45, 368-373.

Ryff, C. D. \& Keyes, C. L. M. (1995). The structure of psychological well- being revisited. Journal of Personality and Social Psychology, 69(4), 719- 727.

Ryff, C. D. (1989). Happiness is everything, or is it? Explorations on the meaning Of psychological well-being. Journal of Personality and Social Psychology, 57, 1069-1081.

Standing, H. (1997). Gender and equity in health sector reform programmes: a review. Health Policy and Planning, 12,1-18.

Taft, A. (2003). Promoting Women's Mental Health: The Challenges of Intimate/Domestic Violence against Women. Australian Domestic Violence Clearinghouse, Issues Paper, 6, 2003.

Thara, R, \& Srinivasan, T.N. (2000). How stigmatising is schizophrenia in India? International Journal of Social Psychiatry. 46(2), 135-41.

Thara, R. \& Srinivasan, L. (1998). Management of social disabilities in schizophrenic. Indian Journal of Psychiatry, 40(4), 331-337.

Thara, R. (2004). The mental health of women: years of neglect and a ray of hope, In Agarwaal, S.P., Goel, D.S., Ichhpujani, R.L., Salhan, R.N., Shrivatsava, S. Mental Health- An Indian perspective (1946-2003), Directorate General of Health Services, Ministry of Health and Family Welfare, New Delhi. Pages, 233-239.

WHO. (1986).The Ottawa Charter for Health Promotion. First International Conference on Health Promotion, Ottawa, 21 November 1986.

WHO. (2000). Women's mental health: an evidence based review, Geneva, World Health Organization: WHO/MSD/MHP/00.1.

WHO. (2008). Gender and women's mental health: gender disparities and mental health: The Facts, accessed at http://www.who.int/mental_health/prevention/genderwomen/en/ on 1st August 2008.

World Bank. (1993). World Development Report 1993: Investing in Health. New York: Oxford University Press.

World Health Organization [WHO]. (1995). Problems and priorities in low-income countries. The New England Journal of Medicine: Research and review, 5, 333, 1227-1228.

How to cite this article: Ashwini R, Prasad V (2017), Women Mental Health and Well-being: A New Paradigm, International Journal of Indian Psychology, Volume 4, Issue 2, No. 92, ISSN:2348-5396 (e), ISSN:2349-3429 (p), DIP:18.01.102/20170402, ISBN:978-1-365-78192-6 